\title{
Facile Fabrication of ZnO-Au Nanocomposite Electrodes for Improved Supercapacitor Properties and Interface Engineering
}

\author{
Xin Zheng ${ }^{1, *}$, Yihui Sun ${ }^{2}$,Sijia Jin ${ }^{1}$, Kang Zhang ${ }^{1}$, Yang Li $^{l}$, Jiaolong Yan ${ }^{l}$, Haiying Qin ${ }^{l}$, Hualiang $\mathrm{Ni}^{1}$ \\ ${ }^{1}$ College of Materials \& Environmental Engineering, Hangzhou Dianzi University, Hangzhou 310018, \\ PR China \\ ${ }^{2}$ Zhejiang Hikstor Technology Co. Ltd, Hangzhou 311300, PR China \\ *E-mail: vencen@hdu.edu.cn
}

doi: $10.20964 / 2020.07 .07$

Received: 7 February 2020 / Accepted: 18 March 2020 / Published: 10 June 2020

\begin{abstract}
Interface engineering is an effective approach to modulate device properties. Here, Au nanoparticles were introduced on $\mathrm{ZnO}$ nanorod surface to tune the electrode/electrolyte interfacial character. As expected, a capacitance of $281 \mathrm{~F} / \mathrm{g}$ could be obtained at a current density of $1 \mathrm{~mA} / \mathrm{cm}^{2}$, which was $53.6 \%$ higher than that without Au nanoparticles. Such enhanced capacitance was due to the Schottky junction at the $\mathrm{Au}$ and $\mathrm{ZnO}$ interface. Specifically, the Schottky heterointerfaces would induce an internal electric field to trap electrons during the charging process so that the additional electrons would be released in the discharge process. In addition, electron transport could be facilitated, and the reaction potential could be lowered because of the Au nanoparticles. The results show the superiority of interface engineering in supercapacitor devices.
\end{abstract}

Keywords: ZnO@Au Nanorod Arrays; Supercapacitor; Interface Engineering; Schottky Barrier

\section{$\underline{\text { FULL TEXT }}$}

(C) 2020 The Authors. Published by ESG (www.electrochemsci.org). This article is an open access article distributed under the terms and conditions of the Creative Commons Attribution license (http://creativecommons.org/licenses/by/4.0/). 